Document downloaded from:

http://hdl.handle.net/10251/60952

This paper must be cited as:

Vendrell Criado, V.; Lhiaubet ., VL.; Cuquerella Alabort, MC.; Miranda Alonso, MÁ. (2013). Photophysical properties of 5-substituted 2-thiopyrimidines. Photochemical \&amp; Photobiological Sciences Photochemical and Photobiological Sciences. 12(8):1460-1465. doi:10.1039/c3pp50058f.

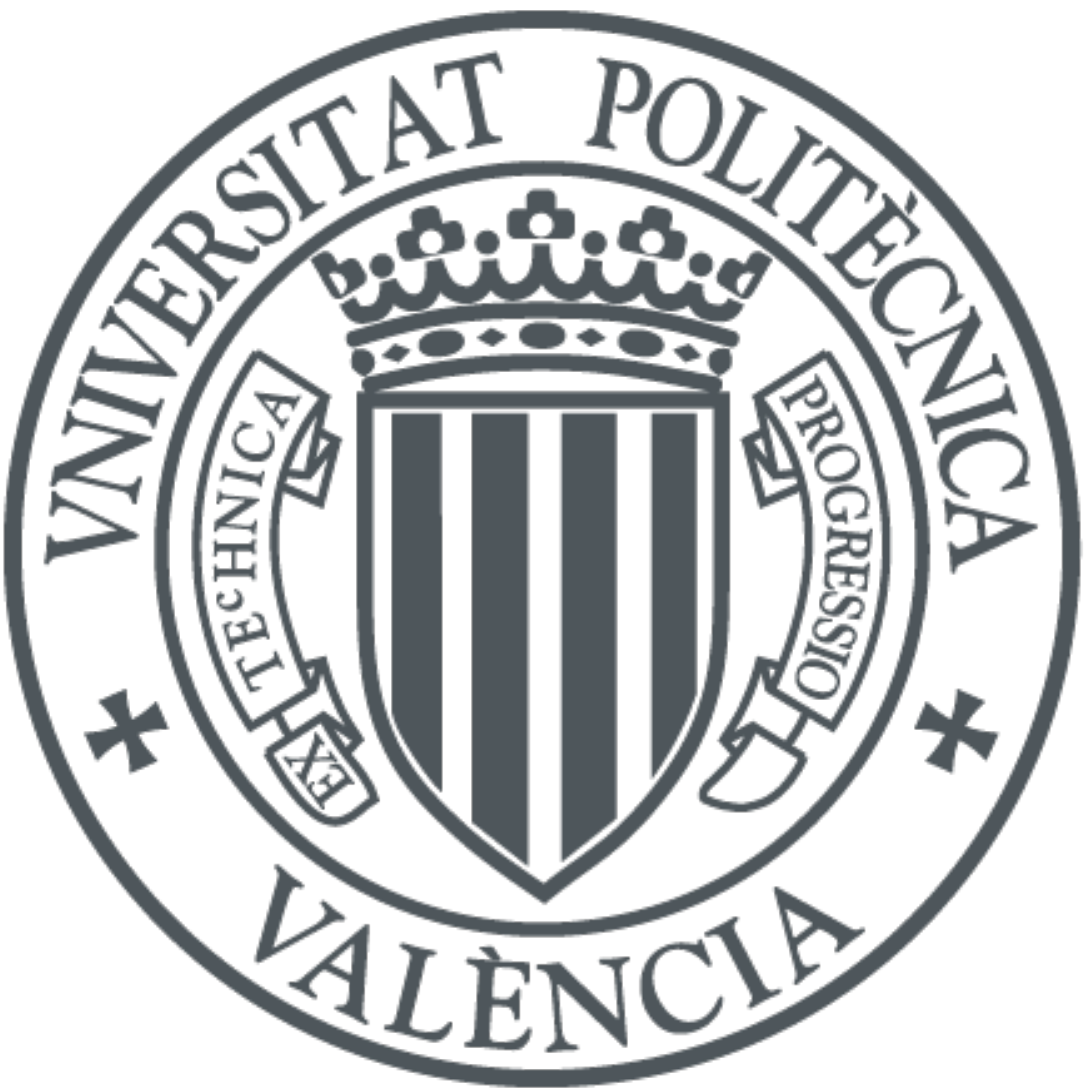

The final publication is available at

http://dx.doi.org/10.1039/c3pp50058f

Copyright Royal Society of Chemistry

Additional Information 


\title{
Photophysical properties of 5-substituted 2-thiopyrimidines
}

\author{
Victoria Vendrell-Criado, Jose A. Sáez, Virginie Lhiaubet-Vallet, M. Consuelo Cuquerella* and Miguel \\ A. Miranda*
}

Received (in $X X X, X X X) X t h X X X X X X X X X 20 X X$, Accepted Xth $X X X X X X X X X 20 X X$

${ }_{5}$ DOI: 10.1039/b000000x

The aim of the present work is to determine the influence of C5 substitution on the photophysical properties of 2-thiopyrimidines (2-TPyr). With this purpose, 2-thiouracil, 5-t-butyl-2-thiouracil and 2thiothymine (TU, BTU and TT, respectively) have been selected as target thionucleobases for the experimental studies and, in parallel, for DFT theoretical calculations. The UV spectra displayed by TU,

${ }_{10} \mathrm{BTU}$ and TT in EtOH were very similar to each other. They showed a maximum around $275 \mathrm{~nm}$ and a shoulder at ca. $290 \mathrm{~nm}$. The three 2-TPyr exhibited a strong phosphorescence emission; from the recorded spectra, triplet excited state energies of ca. 307, 304 and $294 \mathrm{~kJ} / \mathrm{mol}$ were determined for TU, BTU and TT, respectively. Laser excitation at $308 \mathrm{~nm}$ gave rise to a broad transient absorption band from $500 \mathrm{~nm}$ to $700 \mathrm{~nm}$, which was in principle assigned to the triplet-triplet absorption. The triplet lifetimes were 70

$15 \mathrm{~ns}, 1.1 \mu \mathrm{s}$ and $2.3 \mu \mathrm{s}$, for TU, BTU and TT, respectively. This assignment was confirmed by energy transfer experiments, using biphenyl $\left(\mathrm{E}_{\mathrm{T}}=274 \mathrm{~kJ} / \mathrm{mol}\right)$ as acceptor. The obtained photophysical data, both in phosphorescence and transient absorption measurements, point to significantly different properties of the TT triplet excited state in spite of the structural similarities. This behaviour can be satisfactorily explained by theoretical calculations at the B3LYP/aug-cc-pVDZ/PCM level.

\section{${ }_{20}$ Introduction}

Thionucleobases (TNB) are naturally occurring in biological materials. For example, 2-thiouracil is a minor tRNA component found in the wobble position within the anticodon. ${ }^{1}$ Moreover, TNB incorporate easily into the DNA/RNA strands without 25 provoking a significant change in base pairing and are less bulky than conventional crosslinking agents like azidophenacylsubstituted nucleosides. ${ }^{2-3}$ Some of their derivatives show antitumor, antiarthritic and antithyroid activity. ${ }^{4-6}$

The introduction of a thiocarbonyl group in thymine or uracil 30 increases their reactivity and results in modified photophysical features such as a red shifted UV absorption and a dramatic increase of the intersystem crossing quantum yield $\left(\phi_{\text {ISC }} \sim 1\right) .{ }^{7-8}$ This leads to highly reactive triplet excited states able to interact with the canonical nucleobases. Thus, it is possible to achieve 35 selective long-wavelength photoactivation of TNB, making them attractive for mechanistic studies and also as potential prodrugs in photodynamic therapy. ${ }^{6}$ In addition, TNB can be used to perform photo-crosslinking experiments designed to obtain valuable structural information. ${ }^{9-10}$ A specific application is 40 photoactivatable-ribonucleoside-enhanced crosslinking and immunoprecipitation (PAR-CLIP), where photoreactive thioribonucleosides are used for identifying the binding sites of cellular RNA-binding proteins and microRNA-containing ribonucleoprotein complexes. ${ }^{11}$

45 From the photochemical point of view 4-thiopyrimidines have been investigated in depth. By contrast, the 2-thio analogues have attracted comparatively little attention. In this context, 2thiothymine has been recently subjected to phosphorescence 50 emission and transient absorption spectroscopic studies. As a result, highly efficient formation of the excited triplet state has been observed as a structureless band in the 550-700 $\mathrm{nm}$ region; its energy has been estimated at $282 \mathrm{~kJ} / \mathrm{mol}$ and its lifetime at 2.7 $\mu \mathrm{s}$ in $\mathrm{MeCN}$. The experimental results have been correlated with 55 quantum chemical calculations at the B3LYP/6-31+G(d,p)/PCM level. $^{7-8}$

The aim of the present work is to determine the influence of C5 substitution on the photophysical properties of 2thiopyrimidines (2-TPyr). With this purpose, 2-thiouracil, 5- $t$ 60 butyl-2-thiouracil and 2-thiothymine (TU, BTU and TT, respectively, Fig. 1) have been selected as target TNB for the experimental studies and, in parallel, for DFT theoretical calculations.

\section{Materials and methods}

\section{${ }_{65}$ Chemicals}

2-Thiouracil (TCI Europe), 2-thiothymine (Alfa Aesar), biphenyl and benzhydrol (Sigma-Aldrich) were commercial samples and used without further purification. As regards 5-t-butyl-2thiouracil, it was prepared and purified according to the 70 previously reported procedure. ${ }^{12}$ Ethanol and acetonitrile (HPLC grade) were purchased from Scharlau and used as received. 


\section{Absorption and emission spectroscopy}

Absorption spectra were measured with a double beam Varian UV-VIS model Cary 300 Scan spectrophotometer, using $1 \mathrm{~cm}$ pathway quartz cuvettes. Phosphorescence spectra were obtained 5 from a Photon Technology International (PTI, TimeMaster TM2/2003) spectrofluorometer equipped with a pulsed Xe lamp. The apparatus was operated in time-resolved mode, with a delay time of $0.5 \mathrm{~ms}$. Compounds were dissolved in ethanol, placed in quartz tubes ( $5 \mathrm{~mm}$ of diameter) and cooled at $77 \mathrm{~K}$. The samples were 10 excited at $270 \mathrm{~nm}$. Xanthone was used as a reference for determining the phosphorescence quantum yields $\left(\phi_{\mathrm{Ph}}=0.4\right)$.

\section{Laser flash photolysis}

A pulsed Xe/HCl Excimer Laser (LEXTRA50 Lambda Physik LaserTechnik) was used, with $308 \mathrm{~nm}$ as excitation wavelength 15 (10 ns pulse). A Lo255 Oriel Xe lamp was employed as detecting light source. The laser flash photolysis apparatus consisted of the pulsed laser, the Xe lamp, a monochromator (Oriel, model 77200), a photomultiplier system (Oriel, model 70705) and a TDS-640A Tektronix oscilloscope. The output signal from the 20 oscilloscope was transferred to a personal computer. The samples were dissolved in acetonitrile and bubbled with $\mathrm{N}_{2}$. In general, their absorbance was adjusted to $\sim 0.3$ at $308 \mathrm{~nm}$.

For quenching experiments, microlitre volumes of a stock biphenyl solution were used in order to obtain appropriate 25 quencher concentrations in the sample cell (from 0 to $5.210^{-4} \mathrm{M}$ ). The triplet decay traces corresponding to 2-TPyr were monitored at $650 \mathrm{~nm}$, while the concomitant formation of the biphenyl triplet excited state was followed as a growth at $360 \mathrm{~nm}$. Quenching by benzhydrol was performed by addition of up to 0.4 ${ }_{30} \mathrm{M}$ of this compound to samples of 2-TPyr $\left(\mathrm{A}_{308}=0.3\right)$.

\section{Computational details}

Ground-state geometries of TU, BTU and TT were optimised without symmetry constraints. Different exchange-correlation functionals including B3LYP, ${ }^{13-14}$ CAM-B3LYP,${ }^{15} \omega \mathrm{B} 97 \mathrm{XD}^{16}$,

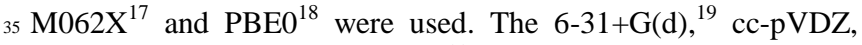
aug-cc-pVDZ and aug-cc-pVTZ ${ }^{20}$ basis sets were employed in the calculations with each DFT functional. All optimised geometries were confirmed to be a true minimum on the potential energy surface through a vibrational frequency calculation. The 40 electronic vertical singlet and triplet transition energies in the Frank-Condon region were computed from the singlet groundstate geometry by using the time-dependent density functional theory (TD-DFT) method ${ }^{21-27}$ employing the same level of theory as for optimisation. The phosphorescence emission energies were 45 computed using a well-established three step approximation: i) optimisation of the triplet excited state geometries with the corresponding unrestricted DFT method, ii) vibrational frequency analysis of the obtained geometry to verify that it is a minimum, iii) calculation of the singlet-triplet excitation energies with a TD50 DFT approach from the excited state geometry. Solvent effects were modelled with the use of the PCM model. ${ }^{28-29}$ All DFT calculations were carried out with Gaussian09 package. $^{30}$ It should be noted that the oscillator strengths of singlet-triplet excitations are set to zero due to the neglected spin-orbital 55 coupling in the triplet TD-DFT calculation in Gausssian09. Finally, from all the twenty DFT method/basis set combinations

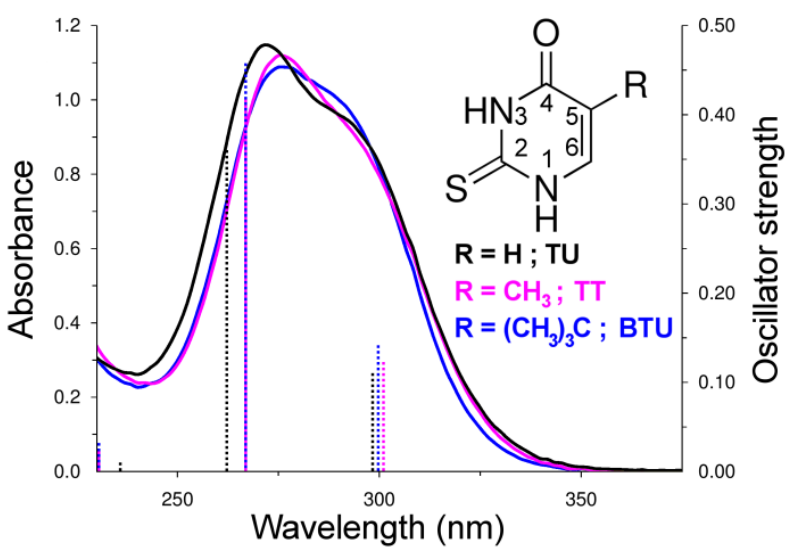

Fig. 1. Absorption spectra of TU, BTU and TT in EtOH and calculated oscillator strength of $S_{1}$ to $S_{6}$ states (dashed lines). Inset: structure of the 2- thiopyrimidines under study

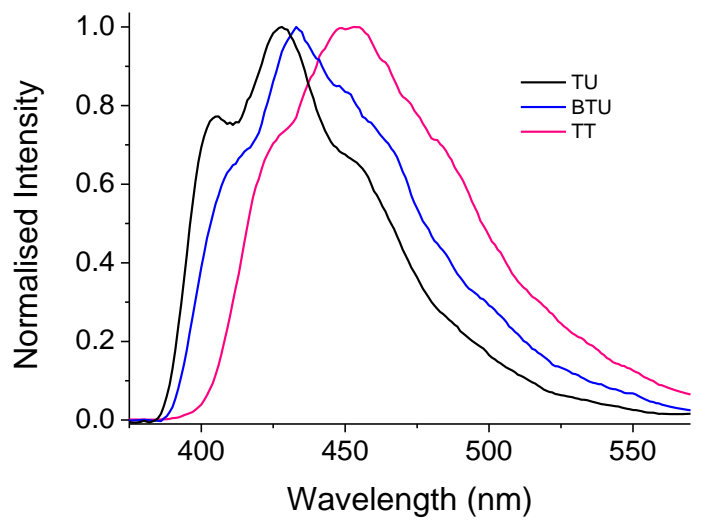

60

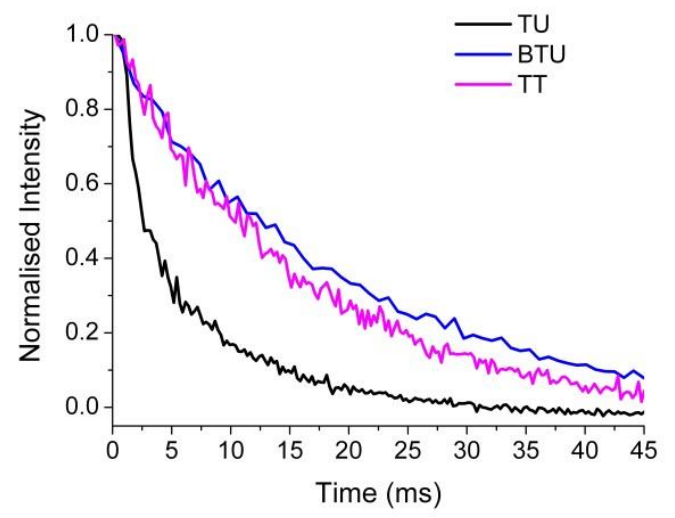

Fig 2. Phosphorescence spectra A) and lifetimes B) of TU, BTU and TT recorded in ethanol glassy matrix at $77 \mathrm{~K}$

used in geometry optimisation and TD-DFT calculations, only B3LYP/aug-cc-pVDZ/PCM results will be discussed, since they ${ }_{65}$ provide the best matching of absorption and emission properties. Full details are included in the Electronic Supplementary Information (ESI) section. 

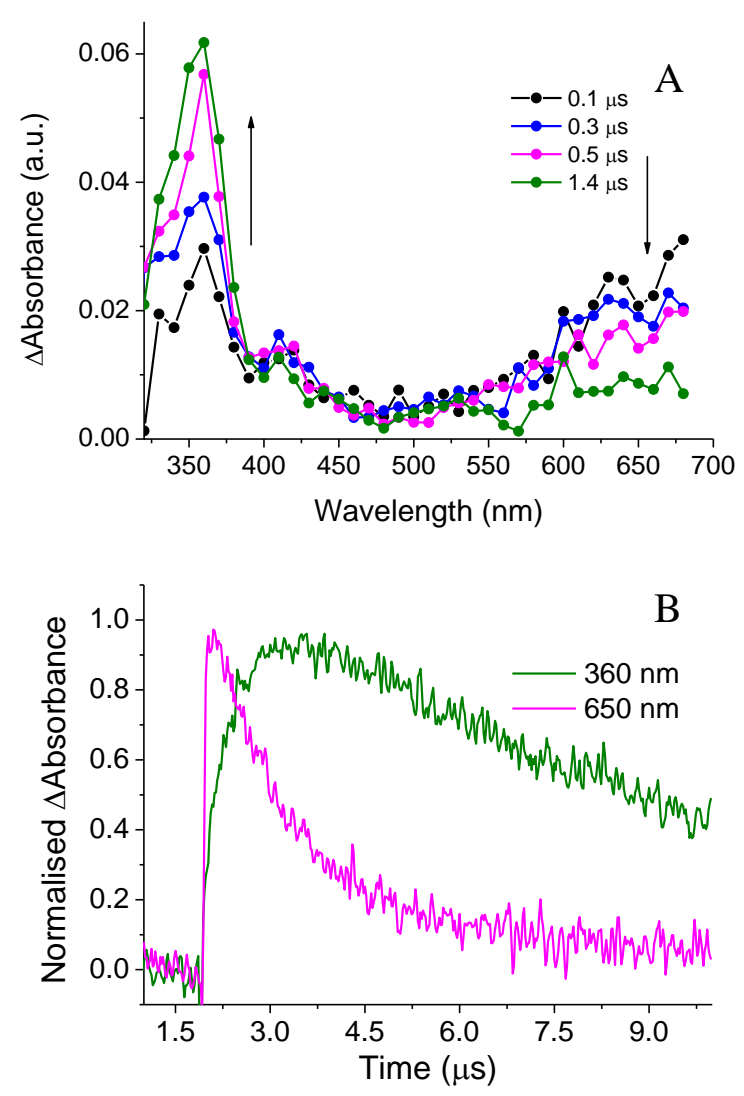

Fig. 3 (A) Transient absorbance changes observed upon laser excitation of 2-thiothymine in $\mathrm{MeCN}$, in the presence of biphenyl $\left(1.7 \times 10^{-4} \mathrm{M}\right)$ as the triplet quencher. (B) Decay and growth traces at $650 \mathrm{~nm}$ and $360 \mathrm{~nm}$

\section{Results and discussion}

\section{Absorption and emission properties of 2-thiopyrimidines}

The UV spectra displayed by TU, BTU and TT in EtOH were very similar to each other. They showed a maximum around 275 $\mathrm{nm}$ and a shoulder at ca. $290 \mathrm{~nm}$ (Fig. 1), with TU $4 \mathrm{~nm}$ blueshifted. No fluorescence emission was observed even when 10 the experiment was performed at $77 \mathrm{~K}$. As expected from the reported data ${ }^{7}$ for related compounds, TU, BTU and TT exhibited a strong phosphorescence emission in ethanol matrix. In spite of their structural similarity, a significant difference was found in the position of the bands (Fig. 2). Thus, maxima at 405, 427 and ${ }_{15} 455 \mathrm{~nm}$ were found for TU, compared with 409, 432 and $463 \mathrm{~nm}$ for BTU. In the case of TT the whole spectrum was ca. $20 \mathrm{~nm}$ red-shifted (maxima at 425, 451 and $483 \mathrm{~nm}$ ). From these spectra triplet excited state energies of ca. 307, 304 and $294 \mathrm{~kJ} / \mathrm{mol}$ were determined from the wavelength corresponding to $10 \%$ intensity 20 for TU, BTU and TT, respectively. Similar phosphorescence quantum yields were determined for the three compounds $\left(\phi_{\mathrm{Ph}}=\right.$ 0.7). Finally, the phosphorescence lifetimes of TU, BTU and TT resulted to be 7,20 and $18 \mathrm{~ms}$; the corresponding decays are shown in Fig. 2B.

\section{${ }_{25}$ Transient absorption spectroscopy}

Laser excitation of TU, BTU and TT at $308 \mathrm{~nm}$ (pulsed $\mathrm{Xe} / \mathrm{HCl}$ excimer laser) gave rise to a broad transient absorption band from

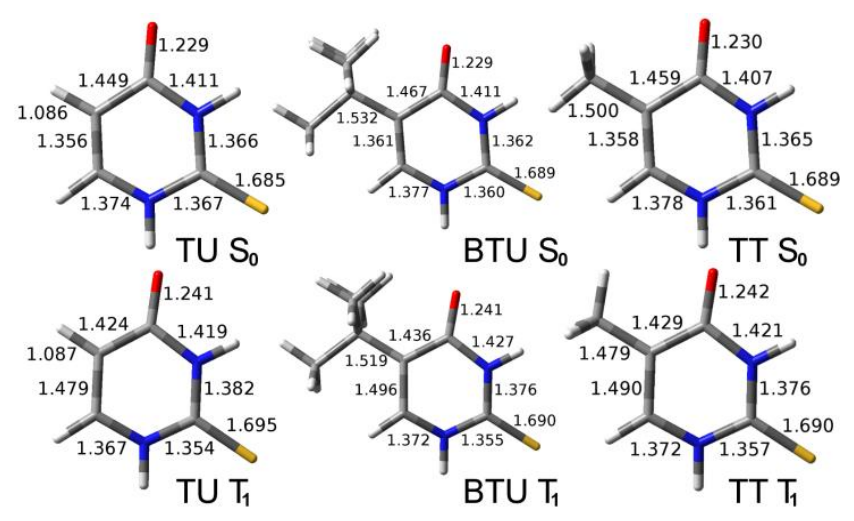

Fig. 4 Optimised geometries for the lowest-lying states of TU, BTU and 30

$500 \mathrm{~nm}$ to $700 \mathrm{~nm}$, which was in principle assigned to the triplettriplet absorption based on the reported spectrum. ${ }^{7}$ No significant change was observed upon bubbling with $\mathrm{N}_{2} \mathrm{O}$. In all cases, the 35 signal decayed with uniform kinetics along the spectrum, indicating the presence of only one transient species. The decay traces at $650 \mathrm{~nm}$ were fitted with a monoexponential function. The lifetimes were $70 \mathrm{~ns}, 1.1 \mu \mathrm{s}$ and $2.3 \mu \mathrm{s}$, for TU, BTU and TT, respectively. To confirm the assignment, triplet-triplet energy 40 transfer experiments were carried out using biphenyl $\left(\mathrm{E}_{\mathrm{T}}=274\right.$ $\mathrm{kJ} / \mathrm{mol})^{31}$ as acceptor. As shown in Fig. 3A for TT, a new band appeared peaking at $360 \mathrm{~nm}$, characteristic of the biphenyl triplet excited state, concomitantly with the disappearance of the signal at $650 \mathrm{~nm}$. The kinetic traces at 360 and $650 \mathrm{~nm}$ are shown in ${ }_{45}$ Fig. 3B for TT. Similar results were obtained for TU and BTU. Further experiments were conducted to determine the electronic configuration of these excited states. With this purpose, the decay kinetics and the transient absorption spectra of TT, BTU and TU were recorded in the presence of benzhydrol as hydrogen donor. ${ }_{50}$ No triplet quenching was observed after addition of up to $0.4 \mathrm{M}$ benzhydrol, neither was formation of the expected ketyl radical $\left(\lambda_{\max }=550 \mathrm{~nm}\right)$ observed. This supports a $\pi \pi^{*}$ nature for the triplet and contrasts with the results of a control experiment using the benzophenone/benzhydrol couple under the same 55 experimental conditions.

The obtained photophysical data, both in phosphorescence and transient absorption measurements, point to significantly different properties of the TT triplet excited state. This behaviour could not be intuitively rationalised in terms of the C5 substitution; hence, 60 theoretical calculations were performed to understand the experimental results.

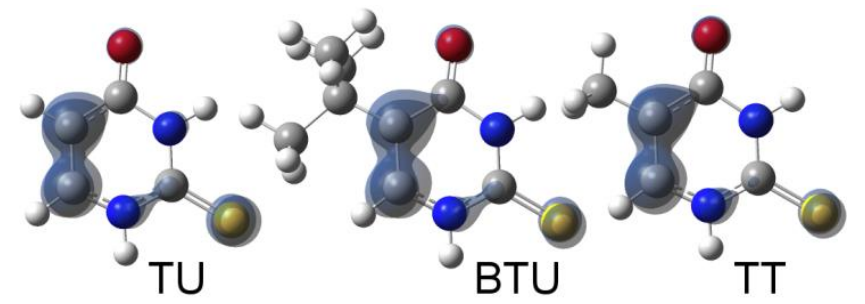

Fig. 5 Spin density plot (0.009 isovalue) of the triplet geometries of TU, BTU and TT at the UB3LYP/aug-cc-pVDZ/PCM level 


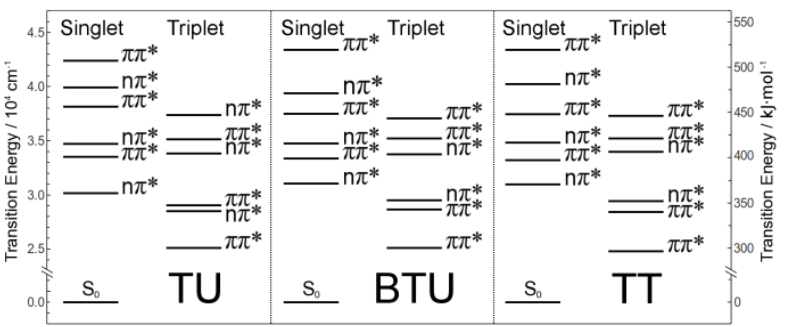

Fig. 6 Energy diagrams of the first six singlet and triplet excited states of TU, BTU and TT. The horizontal bars represent energy levels for the vertical transitions from the ground state computed by the TD-DFT method.

\section{Theoretical calculations}

\section{Geometry and electronic properties}

Geometries of the lowest-lying singlet and triplet states of TU, BTU and TT are shown in Fig. 4. The singlet ground-state 10 geometries belong to the $\mathrm{C}_{\mathrm{s}}$ symmetry group since all atoms lie in the plane of the pyrimidine ring (except two hydrogens of the in-plane methyl group of TT and BTU and two methyl groups of BTU). The bond lengths and angles are nearly equivalent on TU, BTU and TT. The triplet geometries present a bending axis along ${ }_{15} \mathrm{~N} 3$ and C6 atoms to adopt a Dewar-like conformation. Again, the bond lengths and angles on TU, BTU and TT are comparable. At both singlet and triplet geometries, the pyrimidine ring appears to be relatively rigid irrespective of the substitution on $\mathrm{C} 5$. $^{7}$ Although most of the interatomic distances in the $S_{0}$ and $T_{1}$ 20 geometries are similar, a significant lengthening of the C5-C6 bond ( $c a$. 0.12-0.14 $\AA$ ) is observed in the triplet state. Finally, a TD-DFT optimisation for the first and second excited singlet states for the studied 2-TPyr at B3LYP/aug-cc-pVDZ/PCM level was performed, finding a significant elongation of the $\mathrm{C}-\mathrm{S}$ bond ${ }^{7}$ 25 but preserving the $\mathrm{C}_{\mathrm{s}}$ symmetry of the molecules.

To gain insight into the electronic nature of the $T_{1}$ state, the calculated spin density is shown in Fig. 5. In all three bases, spin density is mainly located at the C5 and C6 atoms.

\section{Absorption and emission properties}

30 According to TD-DFT calculations in the Frank-Condon region, the first six singlet-singlet excitations from the ground state $S_{0}$ share identical characteristics throughout TU, BTU and TT (see Table 1 and Fig. 6). In this way, $S_{1}$ involves mainly a transition from the $\mathrm{n}$ orbital located mostly on the sulphur atom (HOMO-1) 35 to the $\pi^{*}$ orbital with antibonding character extending over the $\mathrm{N} 1-\mathrm{C} 2, \mathrm{C} 2-\mathrm{S}$ and $\mathrm{C} 2-\mathrm{N} 3$ bonds (LUMO). The $\mathrm{S}_{2}$ state is mainly associated with the transition from the HOMO orbital $(\pi)$, located on the sulphur atom, to the LUMO. The key molecular orbitals HOMO-1, HOMO, LUMO and LUMO+1 are shown in Fig. 7.

40 Therefore, the absorption bands of 2-TPyr would be attributed to the allowed transitions $\mathrm{S}_{0} \rightarrow \mathrm{S}_{2}\left(\pi \pi^{*}\right.$, calculated oscillator strength 0.1095 for TU, 0.1433 for BTU and 0.1245 for TT) and $\mathrm{S}_{0} \rightarrow \mathrm{S}_{4}\left(\pi \pi^{*}\right.$, calculated oscillator strength 0.3642 for $\mathrm{TU}$, 0.4557 for BTU and 0.4156 for TT). The UV simulated spectra 45 obtained from these TD-DFT values for the singlet-singlet transitions agree well with the experimental data (see Fig. 1 and Table 1). Note that the 0.0000 value computed for the $S_{0} \rightarrow S_{1}$ $\left(\mathrm{n} \pi^{*}\right)$ transition of these 2-TPyr may correspond to any value under 0.0001 .

50 The vertical $\mathrm{S}_{0} \rightarrow \mathrm{T}_{1}\left(\pi \pi^{*}\right)$ transition values computed for the 2-TPyr at B3LYP/aug-cc-pVDZ/PCM level (299.9 kJ/mol for TU, $300.5 \mathrm{~kJ} / \mathrm{mol}$ for BTU and $296.7 \mathrm{~kJ} / \mathrm{mol}$ for TT) are in the same range as the experimentally observed triplet energy values (see Table 1 and Fig. 6). A triplet excited state optimisation at 55 UB3LYP/aug-cc-pVDZ/PCM level of their geometries, followed by a singlet-triplet TD-DFT calculation at the same level gave vertical energy transition values slightly higher $(316.8 \mathrm{~kJ} / \mathrm{mol}$ for TU, $314.1 \mathrm{~kJ} / \mathrm{mol}$ for BTU and $318.1 \mathrm{~kJ} / \mathrm{mol}$ for TT) but still comparable to the experimental values.

60

\begin{tabular}{|c|c|c|c|c|c|}
\hline \multicolumn{6}{|l|}{$\mathrm{TU}$} \\
\hline State & Excitation & $\Delta \mathbf{E}(\mathrm{eV})$ & $\Delta \mathbf{E}(\mathrm{kJ} / \mathrm{mol})$ & nm & $\begin{array}{c}\text { Oscillator } \\
\text { strength }\end{array}$ \\
\hline $\mathrm{S}_{1}\left(\mathrm{n} \pi^{*}\right)$ & $\mathrm{H}-1 \rightarrow \mathrm{L}$ & 3.74 & 361.1 & 331.6 & 0.0000 \\
\hline $\mathrm{S}_{2}\left(\pi \pi^{*}\right)$ & $\mathrm{H} \rightarrow \mathrm{L}$ & 4.16 & 401.4 & 298.3 & 0.1095 \\
\hline $\mathrm{S}_{3}\left(\mathrm{n} \pi^{*}\right)$ & $\mathrm{H}-1 \rightarrow \mathrm{L}+1$ & 4.31 & 415.9 & 287.9 & 0.0003 \\
\hline $\mathrm{S}_{4}\left(\pi \pi^{*}\right)$ & $\mathrm{H} \rightarrow \mathrm{L}+1$ & 4.73 & 456.8 & 262.1 & 0.3642 \\
\hline $\mathrm{S}_{5}\left(\mathrm{n} \pi^{*}\right)$ & $\mathrm{H}-3 \rightarrow \mathrm{L}$ & 4.95 & 478.1 & 250.4 & 0.0002 \\
\hline $\mathrm{S}_{6}\left(\pi \pi^{*}\right)$ & $\mathrm{H}-2 \rightarrow \mathrm{L}$ & 5.26 & 507.7 & 235.8 & 0.0052 \\
\hline $\mathrm{T}_{1}\left(\pi \pi^{*}\right)$ & $\mathrm{H} \rightarrow \mathrm{L}$ & 3.11 & 300.1 & 398.9 & - \\
\hline $\mathrm{T}_{2}\left(\mathrm{n} \pi^{*}\right)$ & $\mathrm{H}-1 \rightarrow \mathrm{L}$ & 3.54 & 341.7 & 350.4 & - \\
\hline $\mathrm{T}_{3}\left(\pi \pi^{*}\right)$ & $\mathrm{H} \rightarrow \mathrm{L}+1$ & 3.60 & 348.0 & 344.0 & - \\
\hline $\mathrm{T}_{4}\left(\mathrm{n} \pi^{*}\right)$ & $\mathrm{H}-1 \rightarrow \mathrm{L}+1$ & 4.20 & 405.0 & 295.6 & - \\
\hline $\mathrm{T}_{5}\left(\pi \pi^{*}\right)$ & $\mathrm{H}-2 \rightarrow \mathrm{L}$ & 4.35 & 420.2 & 284.9 & - \\
\hline $\mathrm{T}_{6}\left(\mathrm{n} \pi^{*}\right)$ & $\mathrm{H}-3 \rightarrow \mathrm{L}$ & 4.63 & 447.2 & 267.7 & - \\
\hline \multicolumn{6}{|l|}{ BTU } \\
\hline $\mathrm{S}_{1}\left(\mathrm{n} \pi^{*}\right)$ & $\mathrm{H}-1 \rightarrow \mathrm{L}$ & 3.85 & 371.9 & 321.9 & 0.0000 \\
\hline $\mathrm{S}_{2}\left(\pi \pi^{*}\right)$ & $\mathrm{H} \rightarrow \mathrm{L}$ & 4.14 & 399.6 & 299.6 & 0.1433 \\
\hline $\mathrm{S}_{3}\left(\mathrm{n} \pi^{*}\right)$ & $\mathrm{H}-1 \rightarrow \mathrm{L}+1$ & 4.31 & 416.6 & 287.4 & 0.0003 \\
\hline $\mathrm{S}_{4}\left(\pi \pi^{*}\right)$ & $\mathrm{H} \rightarrow \mathrm{L}+1$ & 4.65 & 448.9 & 266.7 & 0.4557 \\
\hline $\mathrm{S}_{5}\left(\mathrm{n} \pi^{*}\right)$ & $\mathrm{H}-3 \rightarrow \mathrm{L}$ & 4.89 & 471.7 & 253.8 & 0.0002 \\
\hline $\mathrm{S}_{6}\left(\pi \pi^{*}\right)$ & $\mathrm{H} \rightarrow \mathrm{L}+2$ & 5.38 & 519.6 & 230.4 & 0.0325 \\
\hline $\mathrm{T}_{1}\left(\pi \pi^{*}\right)$ & $\mathrm{H} \rightarrow \mathrm{L}$ & 3.11 & 300.7 & 398.1 & - \\
\hline $\mathrm{T}_{2}\left(\pi \pi^{*}\right)$ & $\mathrm{H} \rightarrow \mathrm{L}+1$ & 3.55 & 343.2 & 348.8 & - \\
\hline $\mathrm{T}_{3}\left(\mathrm{n} \pi^{*}\right)$ & $\mathrm{H}-1 \rightarrow \mathrm{L}$ & 3.66 & 353.4 & 338.8 & - \\
\hline $\mathrm{T}_{4}\left(\mathrm{n} \pi^{*}\right)$ & $\mathrm{H}-1 \rightarrow \mathrm{L}+1$ & 4.19 & 404.5 & 296.0 & - \\
\hline $\mathrm{T}_{5}\left(\pi \pi^{*}\right)$ & $\mathrm{H}-2 \rightarrow \mathrm{L}$ & 4.36 & 421.4 & 284.1 & - \\
\hline $\mathrm{T}_{6}\left(\mathrm{n} \pi^{*}\right)$ & $\mathrm{H}-3 \rightarrow \mathrm{L}$ & 4.59 & 443.3 & 270.1 & - \\
\hline \multicolumn{6}{|l|}{$\mathrm{TT}$} \\
\hline $\mathrm{S}_{1}\left(\mathrm{n} \pi^{*}\right)$ & $\mathrm{H}-1 \rightarrow \mathrm{L}$ & 3.84 & 370.9 & 322.8 & 0.0000 \\
\hline $\mathrm{S}_{2}\left(\pi \pi^{*}\right)$ & $\mathrm{H} \rightarrow \mathrm{L}$ & 4.12 & 397.8 & 301.0 & 0.1245 \\
\hline $\mathrm{S}_{3}\left(\mathrm{n} \pi^{*}\right)$ & $\mathrm{H}-1 \rightarrow \mathrm{L}+1$ & 4.31 & 416.4 & 287.5 & 0.0003 \\
\hline $\mathrm{S}_{4}\left(\pi \pi^{*}\right)$ & $\mathrm{H} \rightarrow \mathrm{L}+1$ & 4.64 & 448.6 & 266.9 & 0.4156 \\
\hline $\mathrm{S}_{5}\left(\mathrm{n} \pi^{*}\right)$ & $\mathrm{H}-3 \rightarrow \mathrm{L}$ & 4.99 & 481.8 & 248.5 & 0.0002 \\
\hline $\mathrm{S}_{6}\left(\pi \pi^{*}\right)$ & $\mathrm{H} \rightarrow \mathrm{L}+2$ & 5.38 & 519.4 & 230.5 & 0.0245 \\
\hline $\mathrm{T}_{1}\left(\pi \pi^{*}\right)$ & $\mathrm{H} \rightarrow \mathrm{L}$ & 3.08 & 296.9 & 403.2 & - \\
\hline $\mathrm{T}_{2}\left(\pi \pi^{*}\right)$ & $\mathrm{H} \rightarrow \mathrm{L}+1$ & 3.53 & 340.5 & 351.6 & - \\
\hline $\mathrm{T}_{3}\left(\mathrm{n} \pi^{*}\right)$ & $\mathrm{H}-1 \rightarrow \mathrm{L}$ & 3.65 & 352.1 & 340.0 & - \\
\hline $\mathrm{T}_{4}\left(\mathrm{n} \pi^{*}\right)$ & $\mathrm{H}-1 \rightarrow \mathrm{L}+1$ & 4.21 & 406.5 & 294.5 & - \\
\hline $\mathrm{T}_{5}\left(\pi \pi^{*}\right)$ & $\mathrm{H}-2 \rightarrow \mathrm{L}$ & 4.36 & 421.3 & 284.2 & - \\
\hline $\mathrm{T}_{6}\left(\pi \pi^{*}\right)$ & $\mathrm{H}-2 \rightarrow \mathrm{L}+1$ & 4.62 & 446.2 & 268.3 & - \\
\hline
\end{tabular}

Table 1. Computed spectroscopic properties for the first six singlet and triplet excited states of TU, BTU and TT at B3LYP/aug-cc-pVDZ/PCM level from TD-DFT calculations: main orbitals involved (H, HOMO; L, $\left.{ }_{65} \mathrm{LUMO}, \ldots\right)$, vertical transition energies $(\Delta \mathrm{E}$ in $\mathrm{eV}, \mathrm{kJ} / \mathrm{mol}$ and $\mathrm{nm})$ and oscillator strength. 


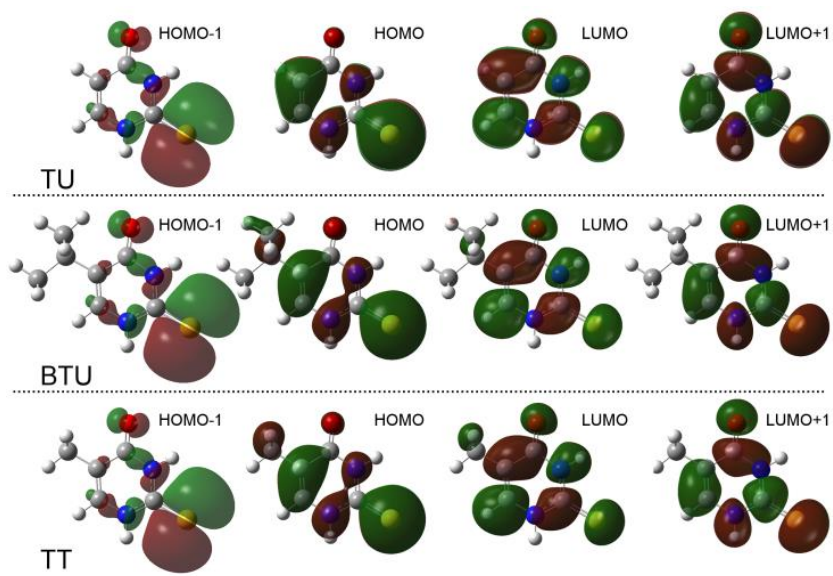

Fig. 7 Molecular orbitals involved in transitions to the $\mathrm{S}_{1}-\mathrm{S}_{4}$ excited singlet states for TU, BTU and TT

\section{Conclusions}

Substitution of 2-thiopyrimidines at C5 modulates the 5 photophysical properties of these thionucleobases,. 2Thiothymine presents the lowest triplet energy whereas 2thiouracil has the shortest triplet lifetime. Theoretical calculations at the B3LYP/aug-cc-pVDZ/PCM level agree well with the experimental range of excited state energies and support the $\pi \pi^{*}$ 10 nature of the lowest triplet states.

\section{Acknowledgements}

Financial support by the Spanish government (CTQ2009-13699, CTQ2012-32621, RyC-2007-00476 to V.L.-V., JAE-Predoc 2011-00740 and JAE-Doc 2010-06204 contracts to V. V-C. and 15 J. A. S. respectively) and computing facilities provided by the Theoretical Organic Chemistry group at the Universitat de Valencia (http://utopia.uv.es) are acknowledged.

\section{Notes and references}

a Instituto de Tecnología Química (UPV-CSIC), Universitat Politècnica 20 de València, 46022 Valencia, Spain, Fax: +34 963877807; Tel: +34 963877809.E-mail: mcuquere@itq.upv.es; mmiranda@qim.upv.es $\dagger$ Electronic Supplementary Information (ESI) available: TU, TBU and TT $S_{0}$ and $T_{1}$ total energies, interatomic distances and singlet-singlet and singlet-triplet TD-DFT vertical transition energies from $\mathrm{S}_{0}$ geometries for

25 all DFT methods/basis set combinations are available. Cartesian coordinates for (U)B3LYP/aug-cc-pVDZ/PCM geometries of TU, TBU and TT $S_{0}$ and $T_{1}$ states are also included. See DOI: 10.1039/b000000x/

1. R. K. Kumar and D. R. Davis, Nucleic Acids Res., 1997, 25, 1272$30 \quad 1280$.

2. H. O. Sintim and E. T. Kool, J. Am. Chem. Soc., 2005, 128, 396-397.

3. A. Favre and J.-L. Fourrey, Acc. Chem. Res., 1995, 28, 375-382.

4. D. S. Cooper, N. Engl. J. Med., 2005, 352, 905-917.

5. S. C. J. Reader, B. Carroll, W. R. Robertson and A. Lambert,

35 Biochem. Pharmacol., 1987, 36, 1825-1828.

6. A. Massey, Y.-Z. Xu and P. Karran, Curr. Biol., 2001, 11, 11421146.

7. H. Kuramochi, T. Kobayashi, T. Suzuki and T. Ichimura, J. Phys. Chem. B, 2010, 114, 8782-8789.

40 8. Y. Harada, C. Okabe, T. Kobayashi, T. Suzuki, T. Ichimura, N. Nishi and Y.-Z. Xu, J. Phys. Chem. Lett., 2009, 1, 480-484.

9. A. Favre, C. Saintomé, J.-L. Fourrey, P. Clivio and P. Laugâa, J. Photochem. Photobiol. B: Biol., 1998, 42, 109-124.
10. R. S. Coleman and J. M. Siedlecki, J. Am. Chem. Soc., 1992, 114, 9229-9230.

11. M. Hafner, M. Landthaler, L. Burger, M. Khorshid, J. Hausser, P. Berninger, A. Rothballer, M. Ascano Jr, A.-C. Jungkamp, M. Munschauer, A. Ulrich, G. S. Wardle, S. Dewell, M. Zavolan and T. Tuschl, Cell, 2010, 141, 129-141.

50 12. I. Basnak, A. Balkan, P. L. Coe and R. T. Walker, Nucleosides \& Nucleotides, 1994, 13, 177-196.

13. A. D. Becke, Phys. Rev. A, 1988, 38, 3098-3100.

14. C. Lee, W. Yang and R. G. Parr, Phys. Rev. B, 1988, 37, 785-789.

15. T. Yanai, D. P. Tew and N. C. Handy, Chem. Phys. Lett., 2004, 393, 51-57.

16. J.-D. Chai and M. Head-Gordon, J. Chem. Phys., 2008, 128, 084106084115 .

17. Y. Zhao and D. Truhlar, Theor. Chem. Acc., 2008, 120, 215-241.

18. C. Adamo and V. Barone, J. Chem. Phys., 1999, 110, 6158-6170.

60 19. R. Ditchfield, W. J. Hehre and J. A. Pople, J. Chem. Phys., 1971, 54, 724-728.

20. J. T. H. Dunning, J. Chem. Phys., 1989, 90, 1007-1023.

21. R. Bauernschmitt and R. Ahlrichs, Chem. Phys. Lett., 1996, 256, $454-$ 464.

65 22. M. E. Casida, C. Jamorski, K. C. Kasida and D. R. Salahub, J. Chem. Phys, 1998, 108, 4439-4449.

23. R. E. Stratmann, G. E. Scuseria and F. M. J., J. Chem. Phys, 1998, 109, 8218-8224.

24. C. Van Caillie and R. D. Amos, Chem. Phys. Lett., 1999, 308, 249255.

25. C. Van Caillie and R. D. Amos, Chem. Phys. Lett., 2000, 317, 159164.

26. F. Furche and R. Ahlrichs, J. Chem. Phys., 2002, 117, 7433-7447.

27. G. Scalmani, M. J. Frisch, B. Mennucci, J. Tomasi, R. Cammi and V. Barone, J. Chem. Phys., 2006, 124, 094107-094115.

28. M. Cossi, G. Scalmani, N. Rega and V. Barone, J. Chem. Phys., 2002, 117, 43-54

29. V. Barone, M. Cossi and J. Tomasi, J. Chem. Phys., 1997, 107, 32103221.

80 30. R. A. Gaussian 09, M. J. Frisch, G. W. Trucks, H. B. Schlegel, G. E. Scuseria, M. A. Robb, J. R. Cheeseman, G. Scalmani, V. Barone, B. Mennucci, G. A. Petersson, H. Nakatsuji, M. Caricato, X. Li, H. P. Hratchian, A. F. Izmaylov, J. Bloino, G. Zheng, J. L. Sonnenberg, M. Hada, M. Ehara, K. Toyota, R. Fukuda, J. Hasegawa, M. Ishida, T. Nakajima, Y. Honda, O. Kitao, H. Nakai, T. Vreven, J. A. Montgomery, Jr., J. E. Peralta, F. Ogliaro, M. Bearpark, J. J. Heyd, E. Brothers, K. N. Kudin, V. N. Staroverov, R. Kobayashi, J. Normand, K. Raghavachari, A. Rendell, J. C. Burant, S. S. Iyengar, J. Tomasi, M. Cossi, N. Rega, J. M. Millam, M. Klene, J. E. Knox, J. B. Cross,

90 V. Bakken, C. Adamo, J. Jaramillo, R. Gomperts, R. E. Stratmann, O. Yazyev, A. J. Austin, R. Cammi, C. Pomelli, J. W. Ochterski, R. L. Martin, K. Morokuma, V. G. Zakrzewski, G. A. Voth, P. Salvador, J. J. Dannenberg, S. Dapprich, A. D. Daniels, Ö. Farkas, J. B. Foresman, J. V. Ortiz, J. Cioslowski, and D. J. Fox, Gaussian, Inc., Wallingford CT, 2009.

31. S. L. Murov, Handbook of Photochemistry, Marcel Dekker Inc., New York, 1973. 